\title{
Understanding the roles of the thylakoid lumen in photosynthesis regulation
}

\author{
Sari Järvi ${ }^{\dagger}$, Peter J. Gollan ${ }^{\dagger}$ and Eva-Mari Aro* \\ Molecular Plant Biology, Department of Biochemistry, University of Turku, Turku, Finland
}

\section{Edited by:}

Suleyman I. Allakhverdiev, Russian

Academy of Sciences, Russia

\section{Reviewed by:}

Suleyman I. Allakhverdiev, Russian Academy of Sciences, Russia

Peter Horton, University of Sheffield, UK

\section{${ }^{*}$ Correspondence:}

Eva-Mari Aro, Molecular Plant Biology, Department of Biochemistry,

University of Turku, FIN-20014 Turku,

Finland

e-mail: evaaro@utu.fi

${ }^{\dagger}$ Sari Järvi and Peter J. Gollan have contributed equally to this work.

It has been known for a long time that the thylakoid lumen provides the environment for oxygen evolution, plastocyanin-mediated electron transfer, and photoprotection. More recently lumenal proteins have been revealed to play roles in numerous processes, most often linked with regulating thylakoid biogenesis and the activity and turnover of photosynthetic protein complexes, especially the photosystem II and NAD(P)H dehydrogenase-like complexes. Still, the functions of the majority of lumenal proteins in Arabidopsis thaliana are unknown. Interestingly, while the thylakoid lumen proteome of at least 80 proteins contains several large protein families, individual members of many protein families have highly divergent roles. This is indicative of evolutionary pressure leading to neofunctionalization of lumenal proteins, emphasizing the important role of the thylakoid lumen for photosynthetic electron transfer and ultimately for plant fitness. Furthermore, the involvement of anterograde and retrograde signaling networks that regulate the expression and activity of lumen proteins is increasingly pertinent. Recent studies have also highlighted the importance of thiol/disulfide modulation in controlling the functions of many lumenal proteins and photosynthetic regulation pathways.

\section{Keywords: NAD(P)H dehydrogenase, photosystem, proteome, thioredoxin, thylakoid lumen}

\section{INTRODUCTION}

Photosystem (PS)I, PSII, and the light harvesting complexes (LHCI and LHCII), in concert with the cytochrome (cyt) $b_{6} f$, ATP synthase, and the $\mathrm{NAD}(\mathrm{P}) \mathrm{H}$ dehydrogenase-like (NDH) are responsible for light harvesting and transduction of solar energy into chemical energy via photosynthetic electron transport (PET). These multi-subunit pigment-protein complexes are embedded in the highly folded thylakoid membrane, which encloses a continuous internal compartment known as the thylakoid lumen. The linear electron transport (LET) chain represents the predominant pathway of PET. Three major thylakoid membrane protein complexes - PSII, cyt $b_{6} f$, and PSI - cooperate in LET in order to transport electrons from water molecules to oxidized nicotinamide adenine dinucleotide phosphate $\left(\mathrm{NADP}^{+}\right)$. Photosynthetic watersplitting occurs at the lumenal side of PSII at the oxygen-evolving complex (OEC). Hydrogen ions accumulating in the lumen as a result of water-splitting and cyt $b_{6} f$ activity generate the proton motive force $(p m f)$ that drives ATP synthesis. Lumenal proton concentration is also an important regulator of PET, triggering non-photochemical quenching (NPQ) of harvested energy and slowing down electron transfer in the cyt $b_{6} f$ complex under acidic lumenal conditions. While LET generates both NADPH and ATP, cyclic electron transport (CET) around PSI produces pmf and thus ATP without reducing NADP ${ }^{+}$(Heber and Walker, 1992). To that end, the main role of PSI CET is to balance the production of ATP and NADPH according to metabolic needs and to alleviate stromal over-reduction (Shikanai, 2007).

Although the photosynthetic apparatus and light-driven electron transport have been studied extensively, there remains a great deal to learn about factors that regulate PET according to the energy requirements of metabolic pathways and environmental cues. Recent characterizations of thylakoid lumen proteomes and analyses of the component proteins have revealed a range of novel proteins and protein families. Furthermore, the details of recent studies show that the lumen holds key factors for regulation and repair of the photosynthetic membrane, facilitating PET flexibility that is vital for efficient energy conversion. Here we review the current understanding of the functions of thylakoid lumen proteins in LET, CET, and PSII repair, and explore factors that regulate their expression, translocation, and activity (Figure 1; Table 1). Although uncharacterized lumen proteins have mainly been excluded from this review, their roles in PET regulation, retrograde signaling and/or acclimation are also likely to be vital for plant growth and development.

\section{DISTINCTIVE FEATURES OF THYLAKOID LUMEN}

A decade ago, the thylakoid lumen was believed to be largely devoid of proteins, containing only the OEC proteins, the electron carrier plastocyanin (PC) and violaxanthin de-epoxidase (VDE). Proteomic and genomic studies have now revealed up to 80 proteins in Arabidopsis thaliana (Arabidopsis) to be localized in this compartment (Peltier et al., 2002; Schubert et al., 2002; Kieselbach and Schroder, 2003). All characterized lumenal proteins in Arabidopsis (Table 1) are nuclear-encoded and post-translationally transported into the chloroplast by the TOC/TIC (translocon at the outer/inner envelope of chloroplasts) system (Soll and Schleiff, 2004), while the secretory (Sec) and twin-arginine translocation (Tat) pathways import proteins into the lumen (discussed below; Albiniak et al., 2012). The thylakoid lumen is a constricted and crowded environment in which protein mobility is largely 


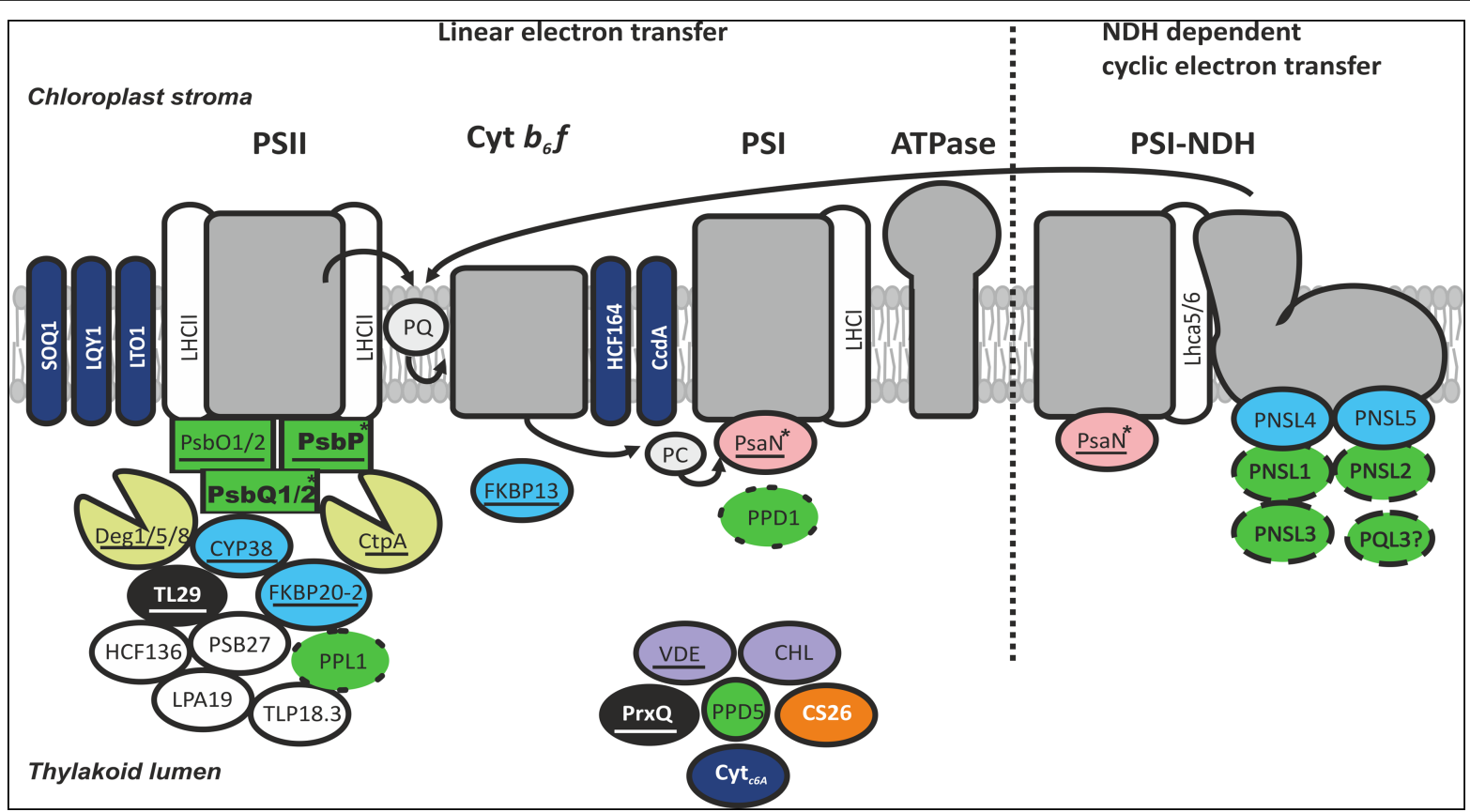

FIGURE 1 | The majority of thylakoid lumen proteins with experimentally verified roles are involved in the function of either the PSIl complex or the PSI-NDH supercomplex. The most abundant protein families in the thylakoid lumen are the OEC and OEC-like proteins (green), the immunophilins (blue), and proteases (yellow). In addition, the lumen proteome comprises peroxidases (black), photoprotective enzymes (purple), and several auxiliary proteins. The OEC proteins are proposed to function in water oxidation (square boxes), granal stacking (bolded), photosystem assembly (dotted outline), strigolactone biosynthesis (circle box), and
$\mathrm{NDH}$-dependent cyclic electron transfer (dashed outline). A high proportion of lumen proteins are thioredoxin targets (underlined). Regulation of thylakoid redox reactions involves membrane-embedded and soluble proteins (dark blue), and other lumen proteins are also implicated (white typeface). Lumen proteins with phosphorylation sites (asterisked) may be regulated by TLP18.3 phosphatase. Based on current knowledge, verified components of lumenal NDH subcomplex are not under post-translational regulation. No characterized lumenal proteins have so far been linked to the function of ATP synthase. restricted; however, the dimensions of the thylakoid lumen are quite flexible (Mullineaux, 2008). Expansion of the lumenal space occurring in high light is linked to light-induced decrease in $\mathrm{pH}$ from around 7.0 in darkness to 5.8 and 6.5 in the light (Kramer et al., 1999; Cruz et al., 2001; Tikhonov, 2013) due the concomitant influx of anions upon acidification (Kirchhoff et al., 2011). The increase in lumenal space under light conditions is thought to allow protein diffusion that is important for PSII maintenance during photosynthetic activity (Kirchhoff et al., 2011). The lumenal $\mathrm{pH}$ controls the activities of many lumenal proteins, effectively functioning as a light-sensing on/off switch (discussed below).

\section{PHOTOSYNTHETIC ELECTRON TRANSFER FROM A LUMENAL PERSPECTIVE WATER-SPLITTING}

The OEC contains a $\mathrm{Mn}_{4} \mathrm{O}_{5} \mathrm{Ca}$ cluster that operates in water oxidation at the lumenal side of PSII. After storing four positive charges as a result of four successive electron transfer steps, the OEC oxidizes two water molecules and releases one oxygen molecule and four protons to the thylakoid lumen. Hence the OEC both liberates electrons for the electron transport chain and participates in acidification of the lumen. The OEC is supported by an extrinsic lumen protein complex, which reversibly associates with intrinsic PSII proteins. The OEC proteins are PsbO (also called OEC33), which is located proximal to the $\mathrm{Mn}_{4} \mathrm{O}_{5} \mathrm{Ca}$ cluster, PsbP (OEC23) and PsbQ (OEC17; Bricker et al., 2012). In Arabidopsis each OEC protein is encoded by two duplicate genes. The PsbO1 isoform exhibits higher oxygen-evolving activity than PsbO2 and accounts for around $90 \%$ of the total PsbO in WT plants (Murakami et al., 2005). PsbQ1 differs from PsbQ2 in a phosphorylatable serine residue that occurs in the latter (Reiland et al., 2009), while the PsbP1 is the major isoform of PsbP in the Columbia-0 ecotype since the PSBP2 gene contains a frameshift that leads to truncated PsbP2 protein that is probably excluded from the thylakoids (Ifuku et al., 2008).

All three OEC proteins are required for maximal oxygen evolution, most likely because they sequester $\mathrm{Cl}^{-}$and $\mathrm{Ca}^{2+}$ ions required for water-splitting (Miqyass et al., 2007; Popelkova and Yocum, 2007). Additionally, each of the OEC proteins appears to have a unique role in the integrity of PSII complexes. PsbQ is important for PSII stability, particularly under low light (Yi et al., 2006), while PsbP is required for assembly and/or stability of PSII and formation of PSII-LHCII supercomplexes (Yi et al., 2007; Ido et al., 2009). PsbQ stabilizes the interaction between PsbP and the membrane-bound PSII subunit PsbR (Suorsa et al., 2006; Allahverdiyeva et al., 2013). These results suggest that PsbP and PsbQ may coordinate the removal and/or reintegration of the $\mathrm{Mn}_{4} \mathrm{O}_{5} \mathrm{Ca}$ cluster with the disassembly and/or reassembly of PSII complexes during the PSII repair cycle (De Las Rivas et al., 2007). 


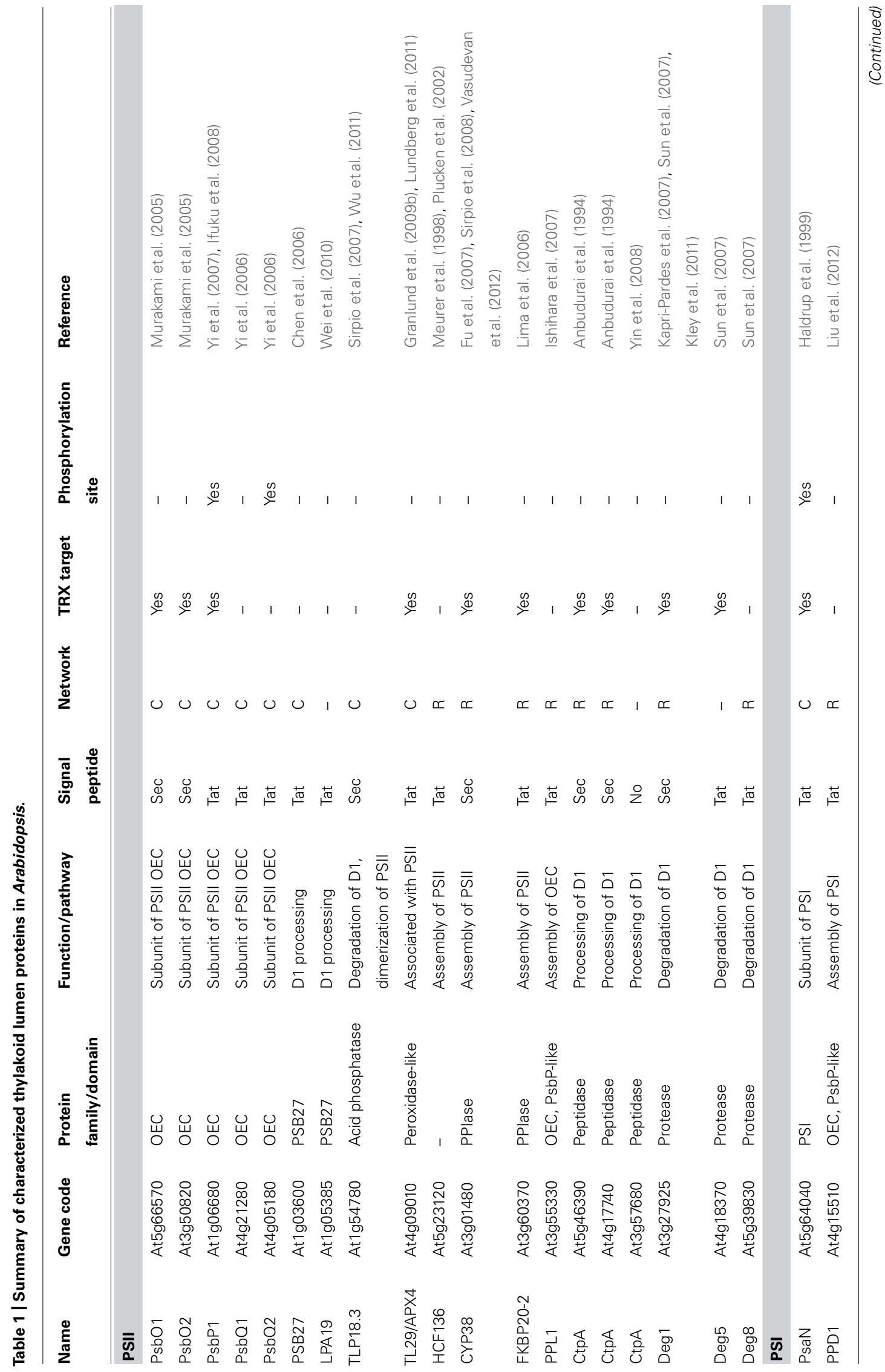




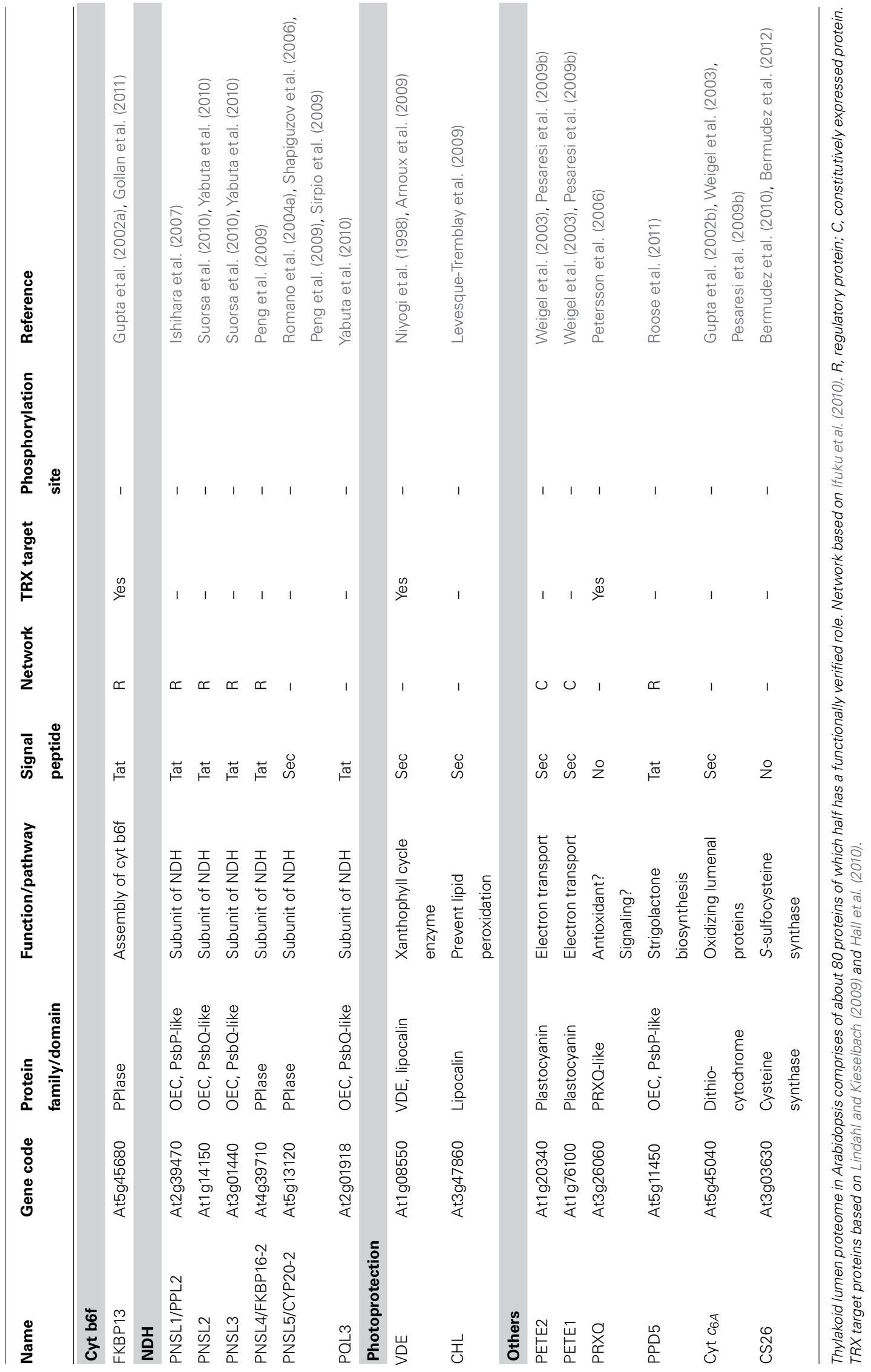


In addition, PsbP and PsbQ are linked to granal stacking (Dekker and Boekema, 2005), but evidence regarding the specific role of PsbQ in thylakoid architecture is contradictory (Yi etal., 2009). PsbO has been described as a GTPase that regulates PSII repair (Spetea et al., 2004; Lundin et al., 2007) and as a carbonic anhydrase (Lu et al., 2005), and has also demonstrated $\mathrm{Ca}^{2+}$ ionbinding activity (Heredia and De Las Rivas, 2003; Murray and Barber, 2006), although all of these features of PsbO are somewhat contentious and remain to be unequivocally demonstrated.

\section{THE 0 CYCLE AND cyt $b_{6} f$}

Part of electrons from PSII is shuttled to cyt $b_{6} f$ via the so-called "Q cycle," which involves successive reduction and oxidation of the membrane-soluble electron- and proton-carrier plastoquinone (PQ). Each Q cycle pumps two protons from the stroma to the lumen, coupling the $\mathrm{pH}$ of the lumen to PET activity (Tikhonov, 2013). A subunit of the cyt $b_{6} f$ complex known as the Rieske protein has a lumenal $[2 \mathrm{Fe}-2 \mathrm{~S}]$ cluster-binding domain that operates in electron transfer between cyt $b_{6}$ and cyt $f$. Rieske interacts with the lumenal immunophilin FKBP13 (Gupta et al., 2002a; Gollan et al., 2011), which was thought to regulate the assembly of the cyt $b_{6} f$ complex from the stromal side (Gupta et al., 2002a), although recent results suggest that the FKBP13-Rieske interaction occurs in the thylakoid lumen (Gollan et al., 2011). The chaperone activity of FKBP13 is sensitive to redox regulation, as discussed below.

\section{PLASTOCYANIN AND PSI}

Electron transfer from cyt $b_{6} f$ to PSI takes place in the lumen, and yet few lumen proteins appear to be directly involved. The major lumenal electron carrier is the copper-containing protein PC, comprising two isoforms in Arabidopsis that are encoded by the PETE1 and PETE2 genes, of which the latter is more highly expressed (Pesaresi et al., 2009b). A cyt $c$ protein that operates as an alternative electron donor for PSI in cyanobacteria and green algae also occurs in the Arabidopsis thylakoid lumen (cyt $c_{6 A}$ ), where it has been suggested to have a similar function (Gupta et al., 2002b); however, strong evidence suggests this is not the case in Arabidopsis (Weigel et al., 2003; Pesaresi et al., 2009b). PsaN is the only lumenal subunit of PSI (Kieselbach and Schroder, 2003). Mutants lacking PsaN are capable of assembling functional PSI complexes and growing photoautotrophically; however, restricted electron flow between PSII and PSI in mutant plants show that PsaN is necessary for efficient interaction between PSI and PC (Haldrup et al., 1999).

\section{CYCLIC ELECTRON TRANSFER}

In PSI CET, electrons are directed from ferredoxin (Fd) back into the $\mathrm{Q}$ cycle rather than to $\mathrm{NADP}^{+}$. The commonly accepted role of CET is in adjusting stromal ATP:NADPH ratios in response to metabolic requirements; however, CET also operates to maintain the low lumenal pH required for NPQ and photosynthetic control of cyt $b_{6} f$ to protect both PSII and PSI, particularly under conditions where PSII is disengaged or inhibited (Kramer et al., 2004; Munekage et al., 2004; Joliot and Johnson, 2011). PSI CET proceeds by two partially redundant pathways; the major route is dependent on proton gradient regulation (PGR) proteins (Munekage et al., 2002; Okegawa et al., 2007) and the formation of a multi-protein CET supercomplex (DalCorso et al., 2008; Iwai etal., 2010), although some of the components remain to be discovered.

The second, minor route for PSI CET involves the membraneintrinsic NADPH dehydrogenase-like (NDH) complex, which also forms a CET-specific supercomplex through association with PSI (Rumeau et al., 2007; Peng et al., 2009). Based on the structural similarities with mitochondrial complex I of the respiratory chain (Friedrich and Weiss, 1997), which oxidizes NADH and reduces ubiquinone in a process that is coupled to proton translocation across the mitochondrial inner membrane, the NDH-like complex is proposed to play a similar role in the thylakoid membrane. However, the physiological relevance, functional mechanism, and regulation of the chloroplast $\mathrm{NDH}$-like complex have not been fully elucidated (Shikanai, 2007; Yamamoto et al., 2011), partly due to the fact that the abundance of NDH-like complexes in the thylakoid membrane is very low (Sazanov et al., 1998). Nevertheless, the complex is known to be stable only when associated with at least two copies of PSI, and the role of NDH in PSI CET and chlororespiration has been established (Peng and Shikanai, 2011).

The NDH-like complex is composed of at least 30 subunits and auxiliary proteins (Ifuku et al., 2011), and thus the PSI$\mathrm{NDH}$ supercomplex is among the largest protein complexes in the thylakoid membrane. The subunits of NDH include both nuclearencoded and plastid-encoded proteins, indicating strict control of expression, protein import and assembly processes. Based on characterization of $n d h$ mutant Arabidopsis lines, the chloroplast $\mathrm{NDH}$ is postulated to comprise four subcomplexes, known as "A," "B," "membrane," and "lumen” subcomplexes (Ifuku et al., 2011), although detailed structural data for any of these is currently missing. The higher plant NDH is closely related to its cyanobacterial counterpart, with the major differences being the lumenal subcomplex and some auxiliary proteins that are characteristic to plant NDH (Peng et al., 2009; Battchikova et al., 2011).

The lumenal subcomplex, which is vital for stability of subcomplex A, comprises a PsbP homolog (PPL2, also called PNSL1), a PsbQ homolog (PNSL2), and immunophilins FKBP16-2 (PNSL4) and CYP20-2 (PNSL5; Peng et al., 2009; Sirpio et al., 2009; Suorsa et al., 2010; Yabuta et al., 2010). Of these PNSL5/CYP20-2 is the sole contributor to cyclophilins (CYP)-mediated lumenal PPIase activity (Shapiguzov et al., 2006) and was initially found to co-migrate with LHCII (Romano et al., 2004a). Incorporation of subcomplex A into the thylakoid membrane is one of the final steps in formation of functional $\mathrm{NDH}$, and it may be a reversible one that can disengage CET or accommodate NDH repair (Peng and Shikanai, 2011). It seems plausible that the lumenal subcomplex could regulate the assembly and/or (more likely) disassembly of $\mathrm{NDH}$ according to the conditions in the thylakoid lumen.

\section{THE PSII ASSEMBLY AND REPAIR INVOLVE A LARGE ARRAY OF LUMENAL PROTEINS}

Photosystem II biogenesis shares many components with the repair cycle occurring after photoinhibition of PSII. The D1 protein in the PSII reaction center is the major target of irreversible photodamage during photosynthesis under high light, leading to NPQ by photoinhibition-related quenching (qI); however, balanced damage and repair of PSII have been shown to occur 
at all light intensities (Tyystjärvi and Aro, 1996). Replacement of damaged D1 requires disassembly of PSII-LHCII complexes, PSII migration from crowded grana thylakoids to the stromal lamellae, D1 removal and replacement, reassembly and finally relocation of functional PSII (Baena-González and Aro, 2002). The lumenal components of PSII biogenesis/repair cycle are discussed below.

Degradation of the damaged D1 protein, carried out primarily by thylakoid-associated FtsH proteases, occurs in cooperation with the lumenal Deg1, Deg5, and Deg8 proteases (Kato etal., 2012). Deg1 is activated by homo-hexamerization in response to $\mathrm{pH}$ changes in the lumen (Kley et al., 2011), and interaction between Deg5 and Deg8 to form an active protease complex may also be pH-dependent (Sun et al., 2007). While activated, Deg proteases specifically degrade lumen-exposed loops of D1 (KapriPardes et al., 2007; Sun et al., 2007). Deg1 has proteolytic activity against other lumenal proteins in vitro, including PC and PsbO, suggesting it may operate as a general protease in the thylakoid lumen (Chassin et al., 2002). In addition to proteolytic activity, Deg1 assists PSII assembly through interaction with the reaction center protein D2 (Sun et al., 2010b). Interestingly, the thylakoid lumen acidic phosphatase TLP18.3 is also involved in the degradation of D1 protein, but also in dimerization of PSII (Sirpio et al., 2007; Wu et al., 2011). Interaction between TLP18.3 and Deg1 (Zienkiewicz etal., 2012) might regulate the protease through dephosphorylation (Spetea and Lundin, 2012). The D1 protein is the primary target of photodamage, but other PSII core proteins are also damaged and degraded, particularly in response to environmental stresses. Stromal Deg7 has been shown to be involved in the proteolysis of photodamaged D1, D2, CP47, and CP43 (Sun et al., 2010a), while stromal FtsH proteases and lumenal Deg1 mediate the degradation of LHCII proteins (Zienkiewicz et al., 2012; Luciński and Jackowski, 2013).

Newly synthesized D1 protein is co-translationally inserted into the thylakoid membrane and the core complex. The latter step is assisted by two lumenal proteins, immunophilin CYP38 and "high chlorophyll fluorescence 136" (HCF136), both of which are present already in the proteome of pre-chloroplastic etioplasts, presumably for prompt D1 assembly during thylakoid biogenesis (Meurer et al., 1998; Kanervo et al., 2008). The HCF136 protein is a prerequisite for the assembly of PSII reaction centers during complex biogenesis, while CYP38 assists the assembly of PSII core complexes during both biogenesis and repair (Meurer et al., 1998; Plucken et al., 2002; Fu et al., 2007; Sirpio et al., 2008). The C-terminal CYP-like domain of CYP38 interacts with the PSII apoprotein, CP47 (Vasudevan et al., 2012). Thus, CYP38 might assist the correct folding and integration of CP47 into the PSII core. An additional role for CYP38 may lie in the regulation of correct conformation of D1 and possibly also CP43 during PSII biogenesis and/or repair and as a negative regulator of the thylakoid protein phosphatase that dephosphorylates PSII core proteins (Fulgosi et al., 1998; Vener et al., 1999; Rokka et al., 2000; Fu et al., 2007; Sirpio et al., 2008). The lumenal immunophilin FKBP20-2 also has a role in PSII complex assembly by a yet unknown mechanism (Lima et al., 2006).

Processing of precursor D1 protein to the mature form by the C-terminal processing protease CtpA (Anbudurai et al., 1994; Yamamoto et al., 2001) is required for integration of the OEC complex to PSII (Roose and Pakrasi, 2004). The lumen proteome of Arabidopsis includes three CtpA homologs. Mutation in one of these genes (At3g57680) does not affect accumulation of the D1 precursor suggesting that there may be functional redundancy between the CtpA homologs (Yin et al., 2008). The lumenal homologs Psb27 and "low PSII accumulation 19" (LPA19) interact with the newly inserted D1 precursor and are involved in processing of nascent D1 during PSII biogenesis in Arabidopsis (Chen et al., 2006; Wei et al., 2010). The Psb27 homolog in cyanobacteria interacts with PSII to prevent premature assembly of the $\mathrm{Mn}_{4} \mathrm{O}_{5} \mathrm{Ca}$ cluster at the lumenal side of PSII (Roose and Pakrasi, 2008), suggesting that the timing of D1 maturation is important in the PSII assembly. The importance of a PsbP homolog PPL1 for the PSII repair cycle was shown by the slow recovery of PSII from photoinhibition in ppll plants (Ishihara et al., 2007). Finally, the lumenal ascorbate peroxidase APX4/TL29 has been described as a lumen-located component and/or auxiliary protein of PSII (Granlund et al., 2009b), although according to its crystal structure its function is unlikely to involve peroxidase activity (Lundberg et al., 2011).

\section{PSI ASSEMBLY IS DEPENDENT ON LUMENAL PsbP-LIKE PROTEIN PPD1}

Compared to PSII, PSI is much more tolerant to, and/or very well protected from photoinhibition, as PSI photodamage exists in vivo only under specific conditions such as chilling temperature (Zhang and Scheller, 2004) or in the deficiency of PGR-dependent CET (Suorsa et al., 2012a,b). So far only one lumenal protein assisting PSI biogenesis, namely the PsbP-like protein PPD1, has been identified. PPD1 interacts directly with PSI reaction center proteins PsaA and PsaB and assists the folding and insertion of these two proteins into the thylakoid membrane (Liu et al., 2012). A lack of PPD1 leads to the loss of PSI and an inability to grow photoautotrophically (Liu et al., 2012).

\section{PHOTOPROTECTION COMPONENTS IN THE THYLAKOID LUMEN}

In naturally fluctuating light conditions, the energy harvested by LHCII can become unbalanced in relation to the capacity of stromal acceptors, thus saturating the electron transport chain and generating reactive oxygen species (ROS) that cause photodamage of membrane proteins (Nishiyama et al., 2006; Murata et al., 2007). In order to protect the photosynthetic machinery amidst natural light conditions, plants use energy dissipation mechanisms (NPQ) that are partially located in the thylakoid lumen (Niyogi et al., 1998).

\section{NON-PHOTOCHEMICAL QUENCHING}

The major NPQ mechanism ( $\mathrm{qE}$ ) is rapid and reversible, involving dissipation of absorbed light energy as heat. This is predominantly achieved through production of the carotenoid zeaxanthin and reorganization of LHCII, both processes that are triggered by acidification of the thylakoid lumen. Upon protonation, lumenal VDE converts from a monomer to a dimer, opening access to the active site that facilitates the conversion of violaxanthin to zeaxanthin (Arnoux et al., 2009). Protonation of the PSII protein PsbS causes a structural rearrangement of PSII-LHCII supercomplexes 
(Li et al., 2000, 2004; Kereïche et al., 2010), although the exact role of PsbS in qE remains to be defined (Johnson and Ruban, 2011).

\section{LUMEN RESPONSE TO OXIDATIVE STRESS}

Cysteine synthesis 26 (CS26) is an S-sulfocysteine synthase and occurs in low abundance in the thylakoid lumen, but it has a vital role in detection of lumenal redox conditions, particularly in long photoperiods (Pesaresi et al., 2009a; Bermudez et al., 2010, 2012). A lack of CS26 led to strong photoinhibition and a systemic ROS response that was accompanied by reduced levels of OEC proteins and PSII assembly factors (Bermudez et al., 2012). CS26 was recently proposed as a ROS sensor through its sensitivity to thiosulfate accumulation in the lumen (Gotor and Romero, 2013). The "chloroplastic lipocalin" (CHL) is involved in photoprotection of thylakoid membrane lipids. CHL accumulates in the thylakoid lumen during environmental stress conditions such as drought and high light, as well as in paraquat and abscisic acid treatments, to protect the thylakoid membrane from peroxidation (LevesqueTremblay et al., 2009).

\section{LUMEN PROTEIN FAMILIES DIVERSE ROLES OF THE PsbP-LIKE AND PsbQ-LIKE PROTEINS}

The PsbP family has at least ten members in the Arabidopsis thylakoid lumen (Hall et al., 2010; Sato, 2010). Aside from the OEC protein PsbP, these are PPL1 and PPL2, involved in PSII repair and NDH stability, respectively (discussed above), and at least seven "PsbP domain" proteins (PPD1-7). An eighth (PPD8) is encoded, but has not been detected at the protein level. The role of PPD1 in PSI assembly has been discussed above, but the specific activities of other PPDs in the lumen remain a mystery in many respects. A homolog of PPD2 in the green alga Chlamydomonas reinhardtii is implicated in the generation of singlet oxygen signals (Brzezowski et al., 2012) and PPD5 knockout in Arabidopsis led to a reduction in $\mathrm{NDH}$ activity and is linked to production of the carotenoid-derived hormone strigolactone (Roose et al., 2011).

Similarly, multiple PsbQ-like proteins occur in the Arabidopsis lumen. PQL1 and PQL2 are lumenal subunits of $\mathrm{NDH}$ (see above), while a third (PQL3) is also required for NDH function, but has not been found in the proteome (Yabuta et al., 2010). The cyanobacterial ancestors of plant PsbP and PsbQ domains, called "cyanoP" and "cyanoQ," respectively, are involved in PSII oxygen evolution, but may have more of an auxiliary role in regulation of OEC structure and assembly. Notably, cyanoP is considerably more closely related, at least in sequence and structure, to PPL1 than to PsbP in plants (Sato, 2010; Jackson et al., 2012). Considering the few details about the PsbP- and PsbQ-like proteins known so far, it is tempting to speculate that expansion of these families in the lumen has provided opportunities for regulating the lumen-exposed parts of various photosynthetic complexes.

\section{LUMENAL IMMUNOPHILINS REGULATE THE ASSEMBLY, MAINTENANCE, AND TURNOVER OF THYLAKOID MEMBRANE PROTEIN COMPLEXES}

The immunophilins include two unrelated protein families, the CYP and the FK506-binding proteins (FKBP), both of which are abundant in the thylakoid lumen proteome (He et al., 2004).
Immunophilins are well known for their ability to rotate the peptide bond of a proline residue, known as PPIase activity, which has been linked to protein folding; however, a majority of the lumenal immunophilins does not show PPIase activity against synthetic peptides (Shapiguzov et al., 2006; Edvardsson et al., 2007). The best characterized of the lumen immunophilins is CYP38, which has an atypical CYP domain in the C-terminus and an N-terminal helical bundle, possibly for autoinhibition (Vasudevan et al., 2012). CYP38 does not show PPIase activity, but has a vital role in the assembly of PSII (Fu et al., 2007; Sirpio et al., 2008). Contrary to earlier observations (He et al., 2004; Romano et al., 2004b; Sirpio et al., 2008), CYP38 in Arabidopsis lacks a leucine zipper domain due to a frameshift in the coding sequence. The spinach ortholog of CYP38, called "thylakoid lumen PPIase of $40 \mathrm{kDa}$ " (TLP40; $82 \%$ sequence identity to CYP38) is likely to possess a similar functional role to CYP38, but appears to behave differently to its Arabidopsis counterpart in that TLP40 has PPIase activity in vitro (Fulgosi et al., 1998; Vener et al., 1999). FKBP20-2 was also implicated in PSII assembly based on the observed increase of unassembled PSII monomers and dimers in the fkbp20-2 knockout, suggesting a role in formation of PSII supercomplexes (Lima et al., 2006). As discussed earlier, FKBP16-2 and CYP20-2 take part in the lumenal NDH subcomplex (Peng et al., 2009), while another immunophilin, FKBP13, is linked to cyt $b_{6} f$ regulation through interaction with Rieske (Gupta et al., 2002a; Gollan et al., 2011). In wheat, FKBP16-1 and FKBP16-3 may have a role in development of photosynthetic membranes through their interaction partners, the PsaL subunit of PSI and "thylakoid formation-1" (THF1, also called PSB29), respectively (Gollan et al., 2011).

The roles of most lumenal immunophilins remain unclear, although accumulating evidence indicates a primary role in the assembly and/or turnover of photosynthetic complexes. FKBP162, FKBP16-4, and CYP37 have been found both in the membranebound and lumen-soluble thylakoid proteomes (Peltier etal., 2002; Friso et al., 2004), suggesting that they may be involved in recruitment of lumen proteins to the membrane.

\section{PENTAPEPTIDE REPEAT PROTEINS IN THYLAKOID LUMEN HAVE UNKNOWN FUNCTION}

A lumenal pentapeptide repeat-containing (PPR) family has three members; TL15, TL17, and TL20.3 (Schubert et al., 2002; Hall et al., 2010). The lumenal pentapeptide proteins TL15 and TL17 in Arabidopsis increase in abundance upon light adaptation (Granlund et al., 2009a) and are, together with TL20.3, putative targets of thioredoxin (TRX) reduction (Hall et al., 2010). In line with this, the crystal structure of TL15 has revealed an internal disulfide bridge (Ni et al., 2011). Cyanobacterial PPRs have diverse roles, two of which may be relevant in the thylakoid lumen; regulation of light-induced manganese ion import (Chandler et al., 2003) and galactolipid translocation (Black et al., 1995).

\section{POST-TRANSLATIONAL MODIFICATIONS OF LUMEN PROTEINS \\ REGULATION OF LUMEN PROTEINS BY REVERSIBLE PHOSPHORYLATION}

Phosphoproteomics studies have identified several phosphorylated proteins in the thylakoid lumen (Table 1), including the 
OEC proteins PsbP and PsbQ (Reiland et al., 2009) and lumenexposed regions of the PSII subunits PsbR and CP47 (Reiland et al., 2009) and the PSI subunits PsaF (Sugiyama etal., 2008) and PsaN (Stael et al., 2012). Phosphorylation of photosynthetic proteins is thought to regulate assembly of the photosynthetic machinery in response to environmental conditions (Reiland et al., 2009). The recent discovery that PsaN phosphorylation is calciumdependent may link PSI maintenance with dark-induced stromal $\mathrm{Ca}^{2+}$ flux (Stael et al., 2012). Despite these results, neither lumenal kinases, nor the physiological significance of phosphorylation events in the lumen have been found, while a single candidate for dephosphorylation activity is the membrane anchored TLP18.3 (Sirpio et al., 2007; Wu et al., 2011), although its substrates are unknown. The existence of any nucleotide-dependent processes in the lumen is contentious (Kieselbach and Schroder, 2003), although accumulating evidence suggests that ATP can be imported to the lumen by a membrane-embedded thylakoid ADP/ATP carrier (TAAC; Thuswaldner et al., 2007), where it is presumed to be available for protein phosphorylation. Recently TAAC was also described as a phosphosulfate channel in the plastid envelope (Gigolashvili et al., 2012). A nucleoside diphosphate kinase 3 (NDK3) found both in the thylakoid lumen and in mitochondria is capable of hydrolyzing ATP to generate GTP thought to be the substrate for GTPase activity of PsbO that is implicated in OEC dissociation for PSII repair cycle (Spetea and Lundin, 2012).

\section{REDOX REGULATION THROUGH DISULFIDE BRIDGE MODULATION}

According to current knowledge, more than $40 \%$ of the lumen proteome may be regulated by redox reactions through modulation of disulfide bonds that control protein translocation and folding and/or enzyme activation (Hall et al., 2010). This observation places lumenal redox enzymes as powerful regulators of numerous processes. In comparison, less than $10 \%$ of stromal proteins are regulated by TRX, although at least $10 \mathrm{TRX}$ isoforms exist in the stroma. Chloroplast redox enzymes have recently been thoroughly reviewed (Lindahl and Kieselbach, 2009; Hall et al., 2010), and will be discussed here only briefly.

The leading candidate for the source of disulfide reduction in the lumen is HCF164, an integral membrane enzyme with a lumenal TRX domain, thought to accept reducing equivalents from stromal TRX via the membrane-localized "cyt $c$ defective A" (CcdA; Motohashi and Hisabori, 2006, 2010). HCF164 interacts with cyt $f$ and the Rieske iron-sulfur protein and is required for assembly of the cyt $b_{6} f$ complex (Lennartz et al., 2001), and is also capable of reducing PsaN (Motohashi and Hisabori, 2006). A similarly membrane-embedded TRX-like protein is the "suppressor of quenching 1" (SOQ1), thought to regulate NPQ through a previously uncharacterized pathway (Brooks et al., 2013). "Low quantum yield of photosystem II" (LQY1) is a thylakoid membrane-bound $\mathrm{Zn}$ finger protein with protein disulfide isomerase activity that interacts with PSII core complexes to modulate disulfide bond formation in PSII subunits during the PSII repair cycle (Lu et al., 2011). "Peroxiredoxin Q" (PRXQ) generally transfers reductants from TRX to hydrogen peroxide for detoxification; however, lumenal PRXQ does not appear to reduce hydrogen peroxide (Petersson et al., 2006).
Disulfide bond formation in the lumen requires an electron acceptor to oxidize thiol groups, although the mechanism for this is not clear. One prospect is lumenal oxygen that is released by watersplitting reactions (Buchanan and Luan, 2005). In an interesting development of this idea, CS26 was proposed to regulate thiol oxidation by production of $S$-sulfocysteine in the lumen (Bermudez et al., 2012). Another candidate thiol oxidase is the lumenal cyt $c_{6}$, which is proposed to shuttle reducing equivalents between thiols and PC (Schlarb-Ridley et al., 2006). Recently the "lumen thiol oxidoreductase 1" (LTO1) protein was found to be a thylakoid membrane-localized enzyme with a lumenal TRX domain that was recently shown to catalyze disulfide bond formation in PsbO in vitro (Karamoko et al., 2011).

Although the mechanisms of thiol/disulfide modulation in the lumen remain unclear, important photosynthetic processes are redox-regulated. Disulfide bond formation is important for folding of PsbO1 and PsbO2, which are susceptible to proteolysis in their unfolded state (Hashimoto et al., 1997; Hall et al., 2010; Karamoko et al., 2011). VDE contains disulfides that are vital for its activity in NPQ (Hall et al., 2010). The substrate-binding/PPIase activity of FKBP13 is controlled by two disulfide bridges that can be reduced and oxidized in vitro by TRX (Gopalan et al., 2004, 2006) and LTO1 (Lu etal., 2013), respectively. This suggests that the interaction between FKBP13 and the Rieske iron-sulfur protein may be linked to redox state of the thylakoid (Gollan et al., 2011). Furthermore, homology between FKBP13 and FKBP16-2 infers similar redox sensitivity for the assembly of the lumenal NDH subcomplex (Gollan et al., 2012), although these possibilities have not been tested experimentally. The activity of lumen immunophilins FKBP20-2 and CYP38 may also be regulated by disulfide bond modulation (Lima et al., 2006; Fu et al., 2007; Sirpio et al., 2008). Identification of lumen TRX targets indicates that the PSII repair cycle and OEC assembly are under redox control (Hall et al., 2010). Finally, a lumen-exposed disulfide bridge is thought to regulate the activity of the membrane-bound LHCII kinase STN7 (Lemeille et al., 2009), although the redox factors responsible have not been found.

\section{PROTEIN TRANSLOCATION INTO THYLAKOID LUMEN}

Four separate methods of protein import into thylakoids are established; the "signal recognition particle-dependent" (SRP) method and the "spontaneous" method insert integral membrane proteins into the thylakoid membrane and are employed by many photosynthetic subunits (Michl et al., 1994; Kim et al., 1999). Lumen proteins are translocated from the chloroplast stroma by either the Sec pathway or the Tat pathway, depending on the signal peptide in the precursor of the passenger protein (Albiniak et al., 2012; Table 1).

The Sec system comprises three components; SecA binds the signal peptide in the passenger protein, hydrolyses ATP and threads the unfolded precursor through a fixed channel in the thylakoid membrane comprising SecE and SecY subunits (Yuan et al., 1994; Laidler etal., 1995; Schuenemann etal., 1999). Sec substrates include PsbO, PC, and VDE (Mori et al., 1999).

Unlike the Sec pathway, the Tat pathway operates independently of ATP hydrolysis, instead deriving energy from the pmf across the thylakoid membrane. The Tat system comprises three integral 
membrane subunits; "high chlorophyll fluorescence 106" (Hcf106) and cpTatC associate together to form a large, hetero-oligomeric complex in the thylakoid membrane, while Tha4 occurs in separate homo-oligomeric complexes. The signal peptides of Tat passengers conserve a central, basic "Arg-Arg" motif that is recognized by the Hcf106-cpTatC receptor complex which, in the presence of suitable pmf, then transiently associates with Tha4, which, according to the current model, forms the translocation pore to conduct the passenger protein through a membrane (Albiniak et al., 2012). According to their signal peptides, all PsbP and PsbQ proteins and their homologs in Arabidopsis are Tat substrates, as are all lumenal FKBPs (including FKBP16-2; Gollan et al., 2012). A compelling feature of the Tat pathway is its capacity to transport folded proteins and protein-cofactor complexes. In the homologous bacterial Tat system, this is a "quality control" mechanism that ensures proper protein folding and cofactor integration prior to protein export (Hynds et al., 1998; Berks et al., 2000). In plants the Tat pathway could similarly facilitate folding and assembly in the relatively stable environment of the chloroplast stroma to underwrite protein and cofactor integrity in the fluctuating conditions of the lumen (Muller and Klosgen, 2005). Furthermore, thylakoid import of folded proteins could abrogate the need for post-translational modifications such as phosphorylation in the lumen. It should be noted that important details of the Tat pathway in plants remain unclear, including (i) the physical mechanism of translocation, (ii) contributions of the pmf components, (iii) involvement of stromal chaperones, and (iv) the conformations, post-translational modifications and complex states of Tat passengers.

\section{RESPONSE OF THE LUMEN PROTEOME TO ENVIRONMENTAL CUES \\ TRANSCRIPTION REGULATION}

The importance of retrograde signals emitted from the chloroplast, and from other sites in the plant cell, in regulating the nuclear expression of photosynthetic proteins is becoming clear (Foyer et al., 2012; Queval and Foyer, 2012). Similar signaling factors are likely to regulate expression of lumenal proteins, which are all encoded in the nucleus (Table 1), and yet elucidation of these signals has received little attention. A recent analysis of the expression profiles divided lumen proteins into two networks; a "constitutive factor" group that included predominantly PSI and PSII subunits and few PSII auxiliary proteins, and a "regulatory factor" group containing NDH subunits, as well as several proteins involved in PSII regulation (Ifuku et al., 2010).

\section{ACCLIMATIONS OF THE LUMEN PROTEOME TO LIGHT AND TEMPERATURE}

Fifteen thylakoid lumen proteins displayed increased abundance in light-adapted Arabidopsis compared to dark-adapted plants indicating that their roles are related to photosynthetic activity (Granlund et al., 2009a). These include OEC proteins PsbP1 and PsbQ2, PSII auxiliary proteins HCF136 and PPL1 as well as major PC (PETE2). Additionally PPD5, two pentapeptide proteins and a group of other functionally uncharacterized thylakoid lumen proteins are up-regulated at the protein level in light compared to darkness (Granlund et al., 2009a). Notably, a majority of the proteins found in higher abundance in the light-adapted lumen are Tat substrates, suggesting that the Tat system may regulate the lumen proteome in response to prevailing light (and other stress) conditions according to the pmf that is generated.

Acclimation to low temperature affects the accumulation of eight thylakoid lumen proteins in Arabidopsis (Goulas et al., 2006). These include PsbO1/2, PsbP1/2 proteins, HCF136, NDH related immunophilin PNSL5/CYP20-2, and two FKBP proteins. The drastic increase in accumulation of PNSL5/CYP20-2, which occurs concomitantly with down-regulation of the Calvin-Benson cycle enzymes during cold acclimation, might be linked to the activation of NDH-dependent CET under such conditions. However, it should be noted that Arabidopsis is a cold-tolerant plant and a different response, e.g., in the accumulation of the NDH-like complex, could be present in rice or other cold-sensitive plant species.

\section{THE IMPORTANCE OF pH AS A REGULATOR OF LUMEN PROTEIN ACTIVITY}

Light-induced protonation of the thylakoid lumen contributes the major portion of the $p m f$ that drives ATP production; however, the acidic lumen is an important factor in many other processes, as reviewed above (Figure 2). Low $\mathrm{pH}$ is required to regulate electron transport, through $\mathrm{qE}$ activation and photosynthetic control of cyt $b_{6} f$ (Bratt etal., 1995; Kramer etal., 2004; Li et al., 2004; Joliot and Johnson, 2011). pH-dependent oligomerization of Deg proteases connects thylakoid lumen $\mathrm{pH}$ to photoinhibition, recovery and the proteolytic breakdown of other lumenal proteins (Hall et al., 2010). Likewise, OEC is known to become inactivated by $\mathrm{pH}$ below 6.0 (Commet et al., 2012). Finally, the light- and dark-induced changes in thylakoid membrane architecture, and the internal dimensions of the thylakoids, are also linked to thylakoid lumen $\mathrm{pH}$ (Kirchhoff et al., 2011). The $\mathrm{pH}$ of the lumen is determined by the respective rates of electron transfer and ATP synthase activity, and regulation of these processes is used to maintain stromal homeostasis (Kramer et al., 2004; Joliot and Johnson, 2011). It stands to reason that other lumenal activities may also be regulated according to metabolic requirements through controlled changes in thylakoid lumen $\mathrm{pH}$.

\section{CONCLUDING REMARKS}

The thylakoid lumen not only provides the environment for oxygen evolution, PC-mediated electron transfer and zeaxanthin formation, but also houses factors that are important for the biogenesis, maintenance and turnover of photosynthetic protein complexes, activity of the NDH-like complex and, based on recent findings, even various signaling cascades. Indeed, most characterized lumenal proteins are linked to the PSII and NDH-like complexes, while only few are associated with PSI or cyt $b_{6} f$ complexes and none have functions related to ATP synthase (Figure 1). A striking feature of the thylakoid lumen proteome is the presence of large protein families such as the OEC-like proteins and immunophilins, suggesting that neofunctionalization of lumenal protein homologs in regulation of photosynthetic complexes has driven the evolution of the lumen proteome. It is evident that lumenal proteins 


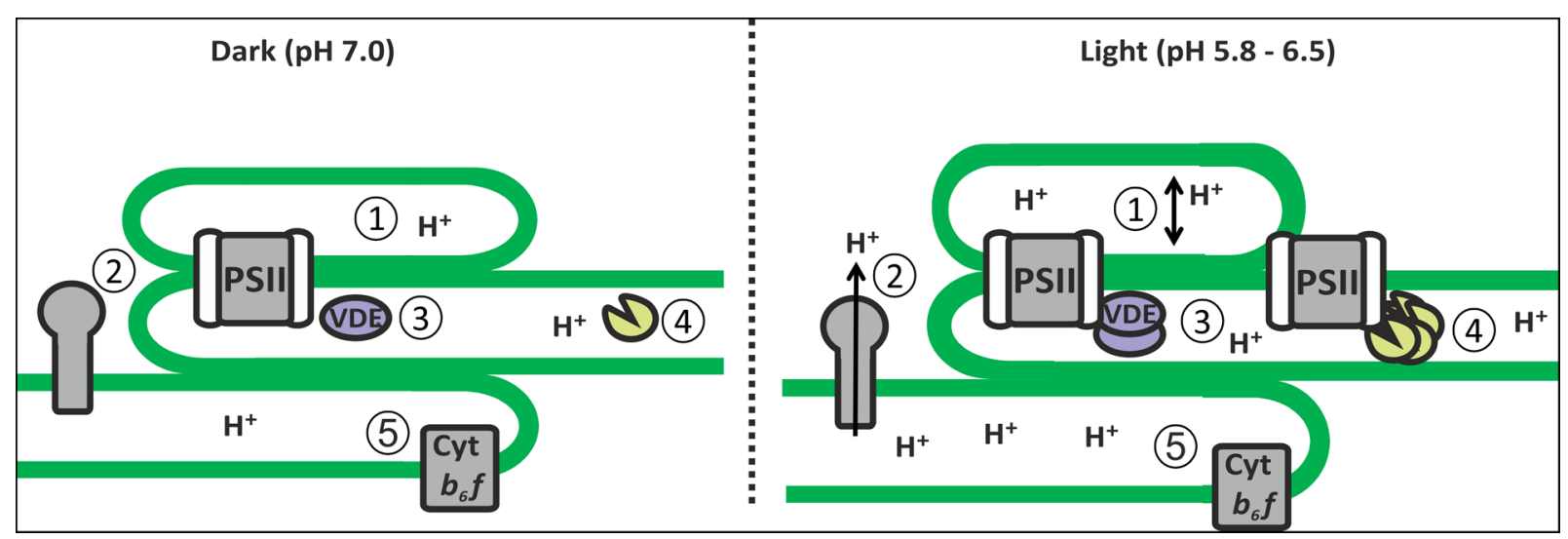

FIGURE 2 | Lumenal processes under pH regulation. (1) Light-induced expansion of the lumen volume facilitating plastocyanin migration and (2) enhancement of ATP synthase activity; (3) Light-induced activation of VDE and PsbS by protonation for photoprotection; (4) Deg oligomerization for PSII repair; and (5) induction of photosynthetic control via cyt $b_{6} f$.

are imported, regulated and degraded directly by changes in the lumenal conditions that reflect the metabolic requirements of the plant. Several novel retrograde and anterograde signaling networks regulating expression and activity of lumen proteins according to environmental cues are likely to be revealed during forthcoming years. To that end, the multitude of photosynthetic regulatory proteins located in the thylakoid lumen should be carefully considered when identifying targets for improving photosynthetic reactions through genetic modifications and/or selection.

\section{ACKNOWLEDGMENT}

This research was supported by the Academy of Finland project 118637.

\section{REFERENCES}

Albiniak, A. M., Baglieri, J., and Robinson, C. (2012). Targeting of lumenal proteins across the thylakoid membrane. J. Exp. Bot. 63, 1689-1698. doi: $10.1093 /$ jxb/err444

Allahverdiyeva, Y., Suorsa, M., Rossi, F., Pavesi, A., Kater, M. M., Antonacci, A., et al. (2013). Arabidopsis plants lacking PsbQ and PsbR subunits of the oxygenevolving complex show altered PSII super-complex organization and short-term adaptive mechanisms. Plant J. 75, 671-684. doi: 10.1111/tpj.12230

Anbudurai, P. R., Mor, T. S., Ohad, I., Shestakov, S. V., and Pakrasi, H. B. (1994). The ctpA gene encodes the C-terminal processing protease for the D1 protein of the photosystem II reaction center complex. Proc. Natl. Acad. Sci. U.S.A. 91, 8082-8086. doi: 10.1073/pnas.91.17.8082

Arnoux, P., Morosinotto, T., Saga, G., Bassi, R., and Pignol, D. (2009). A structural basis for the $\mathrm{pH}$-dependent xanthophyll cycle in Arabidopsis thaliana. Plant Cell 21, 2036-2044. doi: 10.1105/tpc.109.068007

Baena-González, E., and Aro, E. M. (2002). Biogenesis, assembly and turnover of photosystem II units. Philos. Trans. R. Soc. Lond. B Biol. Sci. 357, 1451-1460. doi: 10.1098/rstb.2002.1141

Battchikova, N., Eisenhut, M., and Aro, E. M. (2011). Cyanobacterial NDH-1 complexes: novel insights and remaining puzzles. Biochim. Biophys. Acta 1807, 935-944. doi: 10.1016/j.bbabio.2010.10.017

Berks, B. C., Sargent, F., and Palmer, T. (2000). The Tat protein export pathway. Mol. Microbiol. 35, 260-274. doi: 10.1046/j.1365-2958.2000.01719.x

Bermudez, M. A., Galmes, J., Moreno, I., Mullineaux, P. M., Gotor, C., and Romero, L. C. (2012). Photosynthetic adaptation to length of day is dependent on $S$ sulfocysteine synthase activity in the thylakoid lumen. Plant Physiol. 160, 274-288. doi: 10.1104/pp.112.201491
Bermudez, M. A., Paez-Ochoa, M. A., Gotor, C., and Romero, L. C. (2010). Arabidopsis $S$-sulfocysteine synthase activity is essential for chloroplast function and long-day light-dependent redox control. Plant Cell 22, 403-416. doi: 10.1105/tpc.109.071985

Black, K., Buikema, W. J., and Haselkorn, R. (1995). The hglK gene is required for localization of heterocyst-specific glycolipids in the cyanobacterium Anabaena sp. strain PCC 7120. J. Bacteriol. 177, 6440-6448.

Bratt, C. E., Arvidsson, P., Carlsson, M., and Åkerlund, H. (1995). Regulation of violaxanthin de-epoxidase activity by $\mathrm{pH}$ and ascorbate concentration. Photosynth. Res. 45, 169-175. doi: 10.1007/BF00032588

Bricker, T. M., Roose, J. L., Fagerlund, R. D., Frankel, L. K., and Eaton-Rye, J. J. (2012). The extrinsic proteins of Photosystem II. Biochim. Biophys. Acta 1817, 121-142. doi: 10.1016/j.bbabio.2011.07.006

Brooks, M. D., Sylak-Glassman, E. J., Fleming, G. R., and Niyogi, K. K. (2013). A thioredoxin-like/beta-propeller protein maintains the efficiency of light harvesting in Arabidopsis. Proc. Natl. Acad. Sci. U.S.A. 110, E2733-E2740. doi: 10.1073/pnas.1305443110

Brzezowski, P., Wilson, K. E., and Gray, G. R. (2012). The PSBP2 protein of Chlamydomonas reinhardtii is required for singlet oxygen-dependent signaling. Planta 236, 1289-1303. doi: 10.1007/s00425-012-1683-1

Buchanan, B. B., and Luan, S. (2005). Redox regulation in the chloroplast thylakoid lumen: a new frontier in photosynthesis research. J. Exp. Bot. 56, 1439-1447. doi: $10.1093 /$ jxb/eri158

Chandler, L. E., Bartsevich, V. V., and Pakrasi, H. B. (2003). Regulation of manganese uptake in Synechocystis 6803 by RfrA, a member of a novel family of proteins containing a repeated five-residues domain. Biochemistry 42, 5508-5514. doi: 10.1021/bi027113a

Chassin, Y., Kapri-Pardes, E., Sinvany, G., Arad, T., and Adam, Z. (2002). Expression and characterization of the thylakoid lumen protease DegP1 from Arabidopsis. Plant Physiol. 130, 857-864. doi: 10.1104/pp.007922

Chen, H., Zhang, D., Guo, J., Wu, H., Jin, M., Lu, Q., et al. (2006). A Psb27 homologue in Arabidopsis thaliana is required for efficient repair of photodamaged photosystem II. Plant Mol. Biol. 61, 567-575. doi: 10.1007/s11103-0060031-x

Commet, A., Boswell, N., Yocum, C. F., and Popelka, H. (2012). pH optimum of the photosystem II $\mathrm{H}_{2} \mathrm{O}$ oxidation reaction: effects of PsbO, the manganesestabilizing protein, $\mathrm{Cl}^{-}$retention, and deprotonation of a component required for $\mathrm{O}_{2}$ evolution activity. Biochemistry 51, 3808-3818. doi: 10.1021/bi201678m

Cruz, J. A., Sacksteder, C. A., Kanazawa, A., and Kramer, D. M. (2001). Contribution of electric field $(\Delta \psi)$ to steady-state transthylakoid proton motive force (pmf) in vitro and in vivo. Control of pmf parsing into $\Delta \psi$ and $\Delta \mathrm{pH}$ by ionic strength. Biochemistry 40, 1226-1237. doi: 10.1021/bi0018741

DalCorso, G., Pesaresi, P., Masiero, S., Aseeva, E., Schunemann, D., Finazzi, G., et al. (2008). A complex containing PGRL1 and PGR5 is involved in the switch 
between linear and cyclic electron flow in Arabidopsis. Cell 132, 273-285. doi: 10.1016/j.cell.2007.12.028

Dekker, J. P., and Boekema, E. J. (2005). Supramolecular organization of thylakoid membrane proteins in green plants. Biochim. Biophys. Acta 1706, 12-39. doi: 10.1016/j.bbabio.2004.09.009

De Las Rivas, J., Heredia, P., and Roman, A. (2007). Oxygen-evolving extrinsic proteins (PsbO, P, Q, R): bioinformatic and functional analysis. Biochim. Biophys. Acta 1767, 575-582. doi: 10.1016/j.bbabio.2007.01.018

Edvardsson, A., Shapiguzov, A., Petersson, U. A., Schroder, W. P., and Vener, A. V. (2007). Immunophilin AtFKBP13 sustains all peptidyl-prolyl isomerase activity in the thylakoid lumen from Arabidopsis thaliana deficient in AtCYP20-2. Biochemistry 46, 9432-9442. doi: 10.1021/bi700426q

Foyer, C. H., Neukermans, J., Queval, G., Noctor, G., and Harbinson, J. (2012). Photosynthetic control of electron transport and the regulation of gene expression. $J$. Exp. Bot. 63, 1637-1661. doi: 10.1093/jxb/ers013

Friedrich, T., and Weiss, H. (1997). Modular evolution of the respiratory NADH:ubiquinone oxidoreductase and the origin of its modules. J. Theor. Biol. 187, 529-540. doi: 10.1006/jtbi.1996.0387

Friso, G., Giacomelli, L., Ytterberg, A. J., Peltier, J. B., Rudella, A. Sun, Q., et al. (2004). In-depth analysis of the thylakoid membrane proteome of Arabidopsis thaliana chloroplasts: new proteins, new functions, and a plastid proteome database. Plant Cell 16, 478-499. doi: 10.1105/tpc.017814

Fu, A., He, Z., Cho, H. S., Lima, A., Buchanan, B. B., and Luan, S. (2007). A chloroplast cyclophilin functions in the assembly and maintenance of photosystem II in Arabidopsis thaliana. Proc. Natl. Acad. Sci. U.S.A. 104, 15947-15952. doi: 10.1073/pnas.0707851104

Fulgosi, H., Vener, A. V., Altschmied, L., Herrmann, R. G., and Andersson, B. (1998). A novel multi-functional chloroplast protein: identification of a $40 \mathrm{kDa}$ immunophilin-like protein located in the thylakoid lumen. EMBO J. 17, 15771587. doi: 10.1093/emboj/17.6.1577

Gigolashvili, T., Geier, M., Ashykhmina, N., Frerigmann, H., Wulfert, S., Krueger, S., et al. (2012). The Arabidopsis thylakoid ADP/ATP carrier TAAC has an additional role in supplying plastidic phosphoadenosine $5^{\prime}$-phosphosulfate to the cytosol. Plant Cell 24, 4187-4204. doi: 10.1105/tpc.112.101964

Gollan, P. J., Bhave, M., and Aro, E. M. (2012). The FKBP families of higher plants: exploring the structures and functions of protein interaction specialists. FEBS Lett. 586, 3539-3547. doi: 10.1016/j.febslet.2012.09.002

Gollan, P. J., Ziemann, M., and Bhave, M. (2011). PPIase activities and interaction partners of FK506-binding proteins in the wheat thylakoid. Physiol. Plant. 143 385-395. doi: 10.1111/j.1399-3054.2011.01503.x

Gopalan, G., He, Z., Balmer, Y., Romano, P., Gupta, R., Heroux, A., et al (2004). Structural analysis uncovers a role for redox in regulating FKBP13, an immunophilin of the chloroplast thylakoid lumen. Proc. Natl. Acad. Sci. U.S.A. 101, 13945-13950. doi: 10.1073/pnas.0405240101

Gopalan, G., He, Z., Battaile, K. P., Luan, S., and Swaminathan, K. (2006). Structural comparison of oxidized and reduced FKBP13 from Arabidopsis thaliana. Proteins 65, 789-795. doi: 10.1002/prot. 21108

Gotor, C., and Romero, L. C. (2013). S-sulfocysteine synthase function in sensing chloroplast redox status. Plant Signal. Behav. 8, e23313. doi: 10.4161/psb.23313

Goulas, E., Schubert, M., Kieselbach, T., Kleczkowski, L. A., Gardestrom, P., Schroder, W., et al. (2006). The chloroplast lumen and stromal proteomes of Arabidopsis thaliana show differential sensitivity to short- and long-term exposure to low temperature. Plant J. 47, 720-734. doi: 10.1111/j.1365-313X.2006.02821.x

Granlund, I., Hall, M., Kieselbach, T., and Schroder, W. P. (2009a). Light induced changes in protein expression and uniform regulation of transcription in the thylakoid lumen of Arabidopsis thaliana. PLoS ONE 4:e5649. doi: 10.1371/journal.pone.0005649.

Granlund, I., Storm, P., Schubert, M., Garcia-Cerdan, J. G., Funk, C., and Schroder W. P. (2009b). The TL29 protein is lumen located, associated with PSII and not an ascorbate peroxidase. Plant Cell Physiol. 50, 1898-1910. doi: 10.1093/pcp/ pcp134

Gupta, R., Mould, R. M., He, Z., and Luan, S. (2002a). A chloroplast FKBP interacts with and affects the accumulation of Rieske subunit of cytochrome bf complex. Proc. Natl. Acad. Sci. U.S.A. 99, 15806-15811. doi: 10.1073/pnas.222550399

Gupta, R., He, Z., and Luan, S. (2002b). Functional relationship of cytochrome c6 and plastocyanin in Arabidopsis. Nature 417, 567-571. doi: 10.1038/417567a

Haldrup, A., Naver, H., and Scheller, H. V. (1999). The interaction between plastocyanin and photosystem I is inefficient in transgenic Arabidopsis plants lacking the PSI-N subunit of photosystem I. Plant J. 17, 689-698. doi: 10.1046/j.1365-313X.1999.00419.x

Hall, M., Mata-Cabana, A., Akerlund, H. E., Florencio, F. J., Schroder, W. P., Lindahl, M., et al. (2010). Thioredoxin targets of the plant chloroplast lumen and their implications for plastid function. Proteomics 10, 987-1001.

Hashimoto, A., Ettinger, W. F., Yamamoto, Y., and Theg, S. M. (1997). Assembly of newly imported oxygen-evolving complex subunits in isolated chloroplasts: sites of assembly and mechanism of binding. Plant Cell 9, 441-452.

He, Z., Li, L., and Luan, S. (2004). Immunophilins and parvulins. Superfamily of peptidyl prolyl isomerases in Arabidopsis. Plant Physiol. 134, 1248-1267. doi: 10.1104/pp.103.031005

Heber, U., and Walker, D. (1992). Concerning a dual function of coupled cyclic electron transport in leaves. Plant Physiol. 100, 1621-1626. doi: 10.1104/pp.100.4.1621

Heredia, P., and De Las Rivas, J. (2003). Calcium-dependent conformational change and thermal stability of the isolated PsbO protein detected by FTIR spectroscopy. Biochemistry 42, 11831-11838. doi: 10.1021/bi034582j

Hynds, P. J., Robinson, D., and Robinson, C. (1998). The sec-independent twinarginine translocation system can transport both tightly folded and malfolded proteins across the thylakoid membrane. J. Biol. Chem. 273, 34868-34874. doi: 10.1074/jbc. 273.52.34868

Ido, K., Ifuku, K., Yamamoto, Y., Ishihara, S., Murakami, A., Takabe, K., et al. (2009). Knockdown of the PsbP protein does not prevent assembly of the dimeric PSII core complex but impairs accumulation of photosystem II supercomplexes in tobacco. Biochim. Biophys. Acta 1787, 873-881. doi: 10.1016/j.bbabio.2009.03. 004

Ifuku, K., Endo, T., Shikanai, T., and Aro, E. M. (2011). Structure of the chloroplast NADH dehydrogenase-like complex: nomenclature for nuclear-encoded subunits. Plant Cell Physiol. 52, 1560-1568. doi: 10.1093/pcp/pcr098

Ifuku, K., Ishihara, S., and Sato, F. (2010). Molecular functions of oxygen-evolving complex family proteins in photosynthetic electron flow. J. Integr. Plant. Biol. 52, 723-734. doi: 10.1111/j.1744-7909.2010.00976.x

Ifuku, K., Ishihara, S., Shimamoto, R., Ido, K., and Sato, F. (2008). Structure, function, and evolution of the PsbP protein family in higher plants. Photosynth. Res. 98, 427-437. doi: 10.1007/s11120-008-9359-1

Ishihara, S., Takabayashi, A., Ido, K., Endo, T., Ifuku, K., and Sato, F. (2007). Distinct functions for the two PsbP-like proteins PPL1 and PPL2 in the chloroplast thylakoid lumen of Arabidopsis. Plant Physiol. 145, 668-679. doi: 10.1104/pp.107.105866

Iwai, M., Takizawa, K., Tokutsu, R., Okamuro, A., Takahashi, Y., and Minagawa, J. (2010). Isolation of the elusive supercomplex that drives cyclic electron flow in photosynthesis. Nature 464, 1210-1213. doi: 10.1038/nature08885

Jackson, S. A., Hinds, M. G., and Eaton-Rye, J. J. (2012). Solution structure of CyanoP from Synechocystis sp. PCC 6803: new insights on the structural basis for functional specialization amongst PsbP family proteins. Biochim. Biophys. Acta 1817, 1331-1338. doi: 10.1016/j.bbabio.2012.02.032

Johnson, M. P., and Ruban, A. V. (2011). Restoration of rapidly reversible photoprotective energy dissipation in the absence of PsbS protein by enhanced $\Delta \mathrm{pH}$. J. Biol. Chem. 286, 19973-19981. doi: 10.1074/jbc.M111.237255

Joliot, P., and Johnson, G. N. (2011). Regulation of cyclic and linear electron flow in higher plants. Proc. Natl. Acad. Sci. U.S.A. 108, 13317-13322. doi: 10.1073/pnas.1110189108

Kanervo, E., Singh, M., Suorsa, M., Paakkarinen, V., Aro, E., Battchikova, N., et al. (2008). Expression of protein complexes and individual proteins upon transition of etioplasts to chloroplasts in pea (Pisum sativum). Plant Cell Physiol. 49, 396410. doi: $10.1093 / \mathrm{pcp} / \mathrm{pcn} 016$

Kapri-Pardes, E., Naveh, L., and Adam, Z. (2007). The thylakoid lumen protease Deg1 is involved in the repair of photosystem II from photoinhibition in Arabidopsis. Plant Cell 19, 1039-1047. doi: 10.1105/tpc.106.046573

Karamoko, M., Cline, S., Redding, K., Ruiz, N., and Hamel, P. P. (2011). Lumen thiol oxidoreductase1, a disulfide bond-forming catalyst, is required for the assembly of photosystem II in Arabidopsis. Plant Cell 23, 4462-4475. doi: $10.1105 /$ tpc. 111.089680

Kato, Y., Sun, X., Zhang, L., and Sakamoto, W. (2012). Cooperative D1 degradation in the photosystem II repair mediated by chloroplastic proteases in Arabidopsis. Plant Physiol. 159, 1428-1439. doi: 10.1104/pp.112.199042

Kereïche, S., Kiss, A. Z., Kouøil, R., Boekema, E. J., and Horton, P. (2010). The PsbS protein controls the macro-organisation of photosystem II complexes in 
the grana membranes of higher plant chloroplasts. FEBS Lett. 584, 759-764. doi: 10.1016/j.febslet.2009.12.031

Kieselbach, T., and Schroder, W. P. (2003). The proteome of the chloroplast lumen of higher plants. Photosynth. Res. 78, 249-264. doi: 10.1023/B:PRES.0000006913.86689.f1

Kim, S. J., Jansson, S., Hoffman, N. E., Robinson, C., and Mant, A. (1999). Distinct "assisted" and "spontaneous" mechanisms for the insertion of polytopic chlorophyll-binding proteins into the thylakoid membrane. J. Biol. Chem. 274, 4715-4721. doi: 10.1074/jbc.274.8.4715

Kirchhoff, H., Hall, C., Wood, M., Herbstova, M., Tsabari, O., Nevo, R., et al. (2011). Dynamic control of protein diffusion within the granal thylakoid lumen. Proc Natl. Acad. Sci. U.S.A. 108, 20248-20253. doi: 10.1073/pnas.1104141109

Kley, J., Schmidt, B., Boyanov, B., Stolt-Bergner, P. C., Kirk, R., Ehrmann, M., et al. (2011). Structural adaptation of the plant protease Degl to repair photosystem II during light exposure. Nat. Struct. Mol. Biol. 18, 728-731. doi: 10.1038/nsmb.2055

Kramer, D., Sacksteder, C., and Cruz, J. (1999). How acidic is the lumen. Photosynth. Res. 60, 151-163. doi: 10.1023/A:1006212014787

Kramer, D. M., Avenson, T. J., and Edwards, G. E. (2004). Dynamic flexibility in the light reactions of photosynthesis governed by both electron and proton transfer reactions. Trends Plant Sci. 9, 349-357. doi: 10.1016/j.tplants.2004.05.001

Laidler, V., Chaddock, A. M., Knott, T. G., Walker, D., and Robinson, C. (1995). A SecY homolog in Arabidopsis thaliana. Sequence of a full-length cDNA clone and import of the precursor protein into chloroplasts. J. Biol. Chem. 270, 17664 17667.

Lemeille, S., Willig, A., Depege-Fargeix, N., Delessert, C., Bassi, R., and Rochaix, J. D. (2009). Analysis of the chloroplast protein kinase Stt7 during state transitions. PLoS Biol. 7:e1000045. doi: 10.1371/journal.pbio.1000045.

Lennartz, K., Plucken, H., Seidler, A., Westhoff, P., Bechtold, N., and Meierhoff, K. (2001). HCF164 encodes a thioredoxin-like protein involved in the biogenesis of the cytochrome b(6)f complex in Arabidopsis. Plant Cell 13, 2539 2551.

Levesque-Tremblay, G., Havaux, M., and Ouellet, F. (2009). The chloroplastic lipocalin AtCHL prevents lipid peroxidation and protects Arabidopsis against oxidative stress. Plant J. 60, 691-702. doi: 10.1111/j.1365-313X.2009.03991.x

Li, X.-P., Björkman, O., Shih, C., Grossman, A. R., Rosenquist, M., Jansson, S., et al. (2000). A pigment-binding protein essential for regulation of photosynthetic light harvesting. Nature 403, 391-395. doi: 10.1038/35000131

Li, X. P., Gilmore, A. M., Caffarri, S., Bassi, R., Golan, T., Kramer, D., et al (2004). Regulation of photosynthetic light harvesting involves intrathylakoid lumen pH sensing by the PsbS protein. J. Biol. Chem. 279, 22866-22874. doi: 10.1074/jbc.M402461200

Lima, A., Lima, S., Wong, J. H., Phillips, R. S., Buchanan, B. B., and Luan, S. (2006). A redox-active FKBP-type immunophilin functions in accumulation of the photosystem II supercomplex in Arabidopsis thaliana. Proc. Natl. Acad. Sci. U.S.A. 103, 12631-12636. doi: 10.1073/pnas.0605452103

Lindahl, M., and Kieselbach, T. (2009). Disulphide proteomes and interactions with thioredoxin on the track towards understanding redox regulation in chloroplast and cyanobacteria. J. Proteomics 72, 416-438. doi: 10.1016/j.jprot.2009.01.003

Liu, J., Yang, H., Lu, Q., Wen, X., Chen, F., Peng, L., et al. (2012). PsbP-domain protein1, a nuclear-encoded thylakoid lumenal protein, is essential for photosystem I assembly in Arabidopsis. Plant Cell 24, 4992-5006. doi: 10.1105/tpc.112.106542

Lu, Y., Hall, D. A., and Last, R. L. (2011). A small zinc finger thylakoid protein plays a role in maintenance of photosystem II in Arabidopsis thaliana. Plant Cell 23 1861-1875. doi: 10.1105/tpc.111.085456

Lu, Y., Wang, H. R., Li, H., Cui, H. R., Feng, Y. G., and Wang, X. Y. (2013). A chloroplast membrane protein LTO1/AtVKOR involving in redox regulation and ROS homeostasis. Plant Cell Rep. 32, 1427-1440. doi: 10.1007/s00299-013-1455-9

Lu, Y. K., Theg, S. M., and Stemler, A. J. (2005). Carbonic anhydrase activity of the photosystem II OEC33 protein from pea. Plant Cell Physiol. 46, 1944-1953. doi: $10.1093 / \mathrm{pcp} / \mathrm{pci} 209$

Luciński, R., and Jackowski, G. (2013). AtFtsH heterocomplex-mediated degradation of apoproteins of the major light harvesting complex of photosystem II (LHCII) in response to stresses. J. Plant Physiol. 170, 1082-1089. doi: 10.1016/j.jplph.2013.03.008

Lundberg, E., Storm, P., Schroder, W. P., and Funk, C. (2011). Crystal structure of the TL29 protein from Arabidopsis thaliana: an APX homolog without peroxidase activity. J. Struct. Biol. 176, 24-31. doi: 10.1016/j.jsb.2011.07.004
Lundin, B., Hansson, M., Schoefs, B., Vener, A. V., and Spetea, C. (2007). The Arabidopsis PsbO2 protein regulates dephosphorylation and turnover of the photosystem II reaction centre D1 protein. Plant J. 49, 528-539. doi: 10.1111/j.1365-313X.2006.02976.x

Meurer, J., Plucken, H., Kowallik, K. V., and Westhoff, P. (1998). A nuclearencoded protein of prokaryotic origin is essential for the stability of photosystem II in Arabidopsis thaliana. EMBO J. 17, 5286-5297. doi: 10.1093/emboj/17.18. 5286

Michl, D., Robinson, C., Shackleton, J. B., Herrmann, R. G., and Klosgen, R. B. (1994). Targeting of proteins to the thylakoids by bipartite presequences: CFoII is imported by a novel, third pathway. EMBO J. 13, 1310-1317.

Miqyass, M., van Gorkom, H. J., and Yocum, C. F. (2007). The PSII calcium site revisited. Photosynth Res. 92, 275-287. doi: 10.1007/s11120-006-9124-2

Mori, H., Summer, E. J., Ma, X., and Cline, K. (1999). Component specificity for the thylakoidal Sec and delta $\mathrm{pH}$-dependent protein transport pathways. J. Cell Biol. 146, 45-56.

Motohashi, K., and Hisabori, T. (2006). HCF164 receives reducing equivalents from stromal thioredoxin across the thylakoid membrane and mediates reduction of target proteins in the thylakoid lumen. J. Biol. Chem. 281, 35039-35047. doi: 10.1074/jbc.M605938200

Motohashi, K., and Hisabori, T. (2010). CcdA is a thylakoid membrane protein required for the transfer of reducing equivalents from stroma to thylakoid lumen in the higher plant chloroplast. Antioxid. Redox Signal. 13, 1169-1176. doi: $10.1089 /$ ars. 2010.3138

Muller, M., and Klosgen, R. B. (2005). The Tat pathway in bacteria and chloroplasts (review). Mol. Membr. Biol. 22, 113-121. doi: 10.1080/09687860500041809

Mullineaux, C. W. (2008). Factors controlling the mobility of photosynthetic proteins. Photochem. Photobiol. 84, 1310-1316. doi: 10.1111/j.17511097.2008.00420.x

Munekage, Y., Hashimoto, M., Miyake, C., Tomizawa, K., Endo, T., Tasaka, M., et al. (2004). Cyclic electron flow around photosystem I is essential for photosynthesis. Nature 429, 579-582. doi: 10.1038/nature02598

Munekage, Y., Hojo, M., Meurer, J., Endo, T., Tasaka, M., and Shikanai, T. (2002). PGR5 is involved in cyclic electron flow around photosystem I and is essential for photoprotection in Arabidopsis. Cell 110, 361-371. doi: 10.1016/S0092-8674(02)00867-X

Murakami, R., Ifuku, K., Takabayashi, A., Shikanai, T., Endo, T., and Sato, F. (2005). Functional dissection of two Arabidopsis PsbO proteins: PsbO1 and PsbO2. FEBS J. 272, 2165-2175. doi: 10.1111/j.1742-4658.2005.04636.x

Murata, N., Takahashi, S., Nishiyama, Y., and Allakhverdiev, S. I. (2007). Photoinhibition of photosystem II under environmental stress. Biochim. Biophys. Acta 1767, 414-421. doi: 10.1016/j.bbabio.2006.11.019

Murray, J. W., and Barber, J. (2006). Identification of a calcium-binding site in the PsbO protein of photosystem II. Biochemistry 45, 4128-4130. doi: 10.1021/bi052503t

Ni, S., McGookey, M. E., Tinch, S. L., Jones, A. N., Jayaraman, S., Tong, L., et al. (2011). The 1.7 A resolution structure of At2g44920, a pentapeptide-repeat protein in the thylakoid lumen of Arabidopsis thaliana. Acta Crystallogr. Sect. F Struct. Biol. Cryst. Commun. 67, 1480-1484. doi: 10.1107/S1744309111037432

Nishiyama, Y., Allakhverdiev, S. I., and Murata, N. (2006). A new paradigm for the action of reactive oxygen species in the photoinhibition of photosystem II. Biochim. Biophys. Acta 1757, 742-749. doi: 10.1016/j.bbabio.2006.05. 013

Niyogi, K. K., Grossman, A. R., and Bjorkman, O. (1998). Arabidopsis mutants define a central role for the xanthophyll cycle in the regulation of photosynthetic energy conversion. Plant Cell 10, 1121-1134.

Okegawa, Y., Long, T. A., Iwano, M., Takayama, S., Kobayashi, Y., Covert, S. F., et al. (2007). A balanced PGR5 level is required for chloroplast development and optimum operation of cyclic electron transport around photosystem I. Plant Cell Physiol. 48, 1462-1471. doi: 10.1093/pcp/pcm116

Peltier, J. B., Emanuelsson, O., Kalume, D. E., Ytterberg, J., Friso, G., Rudella, A., et al. (2002). Central functions of the lumenal and peripheral thylakoid proteome of Arabidopsis determined by experimentation and genome-wide prediction. Plant Cell 14, 211-236. doi: 10.1105/tpc.010304

Peng, L., Fukao, Y., Fujiwara, M., Takami, T., and Shikanai, T. (2009). Efficient operation of $\mathrm{NAD}(\mathrm{P}) \mathrm{H}$ dehydrogenase requires supercomplex formation with photosystem I via minor LHCI in Arabidopsis. Plant Cell 21, 3623-3640. doi: $10.1105 /$ tpc. 109.068791 
Peng, L., and Shikanai, T. (2011). Supercomplex formation with photosystem I is required for the stabilization of the chloroplast NADH dehydrogenase-like complex in Arabidopsis. Plant Physiol. 155, 1629-1639. doi: 10.1104/pp.110. 171264

Pesaresi, P., Hertle, A., Pribil, M., Kleine, T., Wagner, R., Strissel, H., et al. (2009a). Arabidopsis STN7 kinase provides a link between short- and longterm photosynthetic acclimation. Plant Cell 21, 2402-2423. doi: 10.1105/tpc.108. 064964

Pesaresi, P., Scharfenberg, M., Weigel, M., Granlund, I., Schroder, W. P., Finazzi, G., et al. (2009b). Mutants, overexpressors, and interactors of Arabidopsis plastocyanin isoforms: revised roles of plastocyanin in photosynthetic electron flow and thylakoid redox state. Mol. Plant. 2, 236-248. doi: 10.1093/mp/ssn041

Petersson, U. A., Kieselbach, T., Garcia-Cerdan, J. G., and Schroder, W. P. (2006). The Prx Q protein of Arabidopsis thaliana is a member of the luminal chloroplast proteome. FEBS Lett. 580, 6055-6061. doi: 10.1016/j.febslet.2006.10.001

Plucken, H., Muller, B., Grohmann, D., Westhoff, P., and Eichacker, L. A. (2002). The HCF136 protein is essential for assembly of the photosystem II reaction center in Arabidopsis thaliana. FEBS Lett. 532, 85-90. doi: 10.1016/S0014-5793(02)03634-7

Popelkova, H., and Yocum, C. F. (2007). Current status of the role of $\mathrm{Cl}(-)$ ion in the oxygen-evolving complex. Photosynth. Res. 93, 111-121. doi: 10.1007/s11120 006-9121-5

Queval, G., and Foyer, C. H. (2012). Redox regulation of photosynthetic gene expression. Philos. Trans. R. Soc. Lond. B Biol. Sci. 367, 3475-3485. doi 10.1098/rstb.2012.0068

Reiland, S., Messerli, G., Baerenfaller, K., Gerrits, B., Endler, A., Grossmann, J., et al. (2009). Large-scale Arabidopsis phosphoproteome profiling reveals novel chloroplast kinase substrates and phosphorylation networks. Plant Physiol. 150, 889-903. doi: 10.1104/pp.109.138677

Rokka, A., Aro, E. M., Herrmann, R. G., Andersson, B., and Vener, A. V. (2000) Dephosphorylation of photosystem II reaction center proteins in plant photosynthetic membranes as an immediate response to abrupt elevation of temperature. Plant Physiol. 123, 1525-1536. doi: 10.1104/pp.123.4.1525

Romano, P. G., Edvardsson, A., Ruban, A. V., Andersson, B., Vener, A. V., Gray, J. E., et al. (2004a). Arabidopsis AtCYP20-2 is a light-regulated cyclophilintype peptidyl-prolyl cis-trans isomerase associated with the photosynthetic membranes. Plant Physiol. 134, 1244-1247. doi: 10.1104/pp.104.041186

Romano, P. G., Horton, P., and Gray, J. E. (2004b). The Arabidopsis cyclophilin gene family. Plant Physiol. 134, 1268-1282. doi: 10.1104/pp.103.022160

Roose, J. L., Frankel, L. K., and Bricker, T. M. (2011). Developmental defects in mutants of the PsbP domain protein 5 in Arabidopsis thaliana. PLoS ONE 6:e28624. doi: 10.1371/journal.pone.0028624

Roose, J. L., and Pakrasi, H. B. (2004). Evidence that D1 processing is required for manganese binding and extrinsic protein assembly into photosystem II. J. Biol. Chem. 279, 45417-45422. doi: 10.1074/jbc.M408458200

Roose, J. L., and Pakrasi, H. B. (2008). The Psb27 protein facilitates manganese cluster assembly in photosystem II. J. Biol. Chem. 283, 4044-4050. doi: 10.1074/jbc.M708960200

Rumeau, D., Peltier, G., and Cournac, L. (2007). Chlororespiration and cyclic electron flow around PSI during photosynthesis and plant stress response. Plant Cell Environ. 30, 1041-1051. doi: 10.1111/j.1365-3040.2007.01675.x

Sato, N. (2010). Phylogenomic and structural modeling analyses of the PsbP superfamily reveal multiple small segment additions in the evolution of photosystem II-associated PsbP protein in green plants. Mol. Phylogenet. Evol. 56, 176-186. doi: 10.1016/j.ympev.2009.11.021

Sazanov, L. A., Burrows, P. A., and Nixon, P. J. (1998). The plastid ndh genes code for an NADH-specific dehydrogenase: isolation of a complex I analogue from pea thylakoid membranes. Proc. Natl. Acad. Sci. U.S.A. 95, 1319-1324. doi: 10.1073/pnas.95.3.1319

Schlarb-Ridley, B. G., Nimmo, R. H., Purton, S., Howe, C. J., and Bendall, D. S. (2006). Cytochrome $\mathrm{c}(6 \mathrm{~A})$ is a funnel for thiol oxidation in the thylakoid lumen. FEBS Lett. 580, 2166-2169. doi: 10.1016/j.febslet.2006.03.052

Schubert, M., Petersson, U. A., Haas, B. J., Funk, C., Schroder, W. P., and Kieselbach, T. (2002). Proteome map of the chloroplast lumen of Arabidopsis thaliana. J. Biol. Chem. 277, 8354-8365. doi: 10.1074/jbc.M108575200

Schuenemann, D., Amin, P., Hartmann, E., and Hoffman, N. E. (1999). Chloroplast $\mathrm{SecY}$ is complexed to SecE and involved in the translocation of the $33-\mathrm{kDa}$ but not the 23-kDa subunit of the oxygen-evolving complex. J. Biol. Chem. 274 12177-12182. doi: 10.1074/jbc.274.17.12177
Shapiguzov, A., Edvardsson, A., and Vener, A. V. (2006). Profound redox sensitivity of peptidyl-prolyl isomerase activity in Arabidopsis thylakoid lumen. FEBS Lett. 580, 3671-3676. doi: 10.1016/j.febslet.2006.05.054

Shikanai, T. (2007). Cyclic electron transport around photosystem I: genetic approaches. Annu. Rev. Plant. Biol. 58, 199-217. doi: 10.1146/annurev.arplant.58.091406.110525

Sirpio, S., Allahverdiyeva, Y., Suorsa, M., Paakkarinen, V., Vainonen, J., Battchikova, N., et al. (2007). TLP18.3, a novel thylakoid lumen protein regulating photosystem II repair cycle. Biochem. J. 406, 415-425. doi: 10.1042/BJ20070460

Sirpio, S., Holmstrom, M., Battchikova, N., and Aro, E. M. (2009). AtCYP20-2 is an auxiliary protein of the chloroplast $\mathrm{NAD}(\mathrm{P}) \mathrm{H}$ dehydrogenase complex. FEBS Lett. 583, 2355-2358. doi: 10.1016/j.febslet.2009.06.031

Sirpio, S., Khrouchtchova, A., Allahverdiyeva, Y., Hansson, M., Fristedt, R., Vener, A. V., et al. (2008). AtCYP38 ensures early biogenesis, correct assembly and sustenance of photosystem II. Plant J. 55, 639-651. doi: 10.1111/j.1365313X.2008.03532.x

Soll, J., and Schleiff, E. (2004). Protein import into chloroplasts. Nat. Rev. 5, 198-208. doi: $10.1038 / \mathrm{nrm} 1333$

Spetea, C., Hundal, T., Lundin, B., Heddad, M., Adamska, I., and Andersson, B. (2004). Multiple evidence for nucleotide metabolism in the chloroplast thylakoid lumen. Proc. Natl. Acad. Sci. U.S.A. 101, 1409-1414. doi: 10.1073/pnas.0308164100

Spetea, C., and Lundin, B. (2012). Evidence for nucleotide-dependent processes in the thylakoid lumen of plant chloroplasts - an update. FEBS Lett. 586, 2946-2954. doi: 10.1016/j.febslet.2012.07.005

Stael, S., Rocha, A. G., Wimberger, T., Anrather, D., Vothknecht, U. C., and Teige, M. (2012). Cross-talk between calcium signalling and protein phosphorylation at the thylakoid. J. Exp. Bot. 63, 1725-1733. doi: 10.1093/jxb/err403

Sugiyama, N., Nakagami, H., Mochida, K., Daudi, A., Tomita, M., Shirasu, K., et al. (2008). Large-scale phosphorylation mapping reveals the extent of tyrosine phosphorylation in Arabidopsis. Mol. Syst. Biol. 4, 193. doi: 10.1038/msb.2008.32

Sun, X., Fu, T., Chen, N., Guo, J., Ma, J., Zou, M., et al. (2010a). The stromal chloroplast Deg7 protease participates in the repair of photosystem II after photoinhibition in Arabidopsis. Plant Physiol. 152, 1263-1273. doi: 10.1104/pp.109.150722

Sun, X., Ouyang, M., Guo, J., Ma, J., Lu, C., Adam, Z., et al. (2010b). The thylakoid protease Deg1 is involved in photosystem-II assembly in Arabidopsis thaliana. Plant J. 62, 240-249. doi: 10.1111/j.1365-313X.2010.04140.x

Sun, X., Peng, L., Guo, J., Chi, W., Ma, J., Lu, C., et al. (2007). Formation of DEG5 and DEG8 complexes and their involvement in the degradation of photodamaged photosystem II reaction center D1 protein in Arabidopsis. Plant Cell 19, 13471361. doi: 10.1105/tpc.106.049510

Suorsa, M., Grieco, M., Jarvi, S., Gollan, P. J., Kangasjarvi, S., Tikkanen, M., et al. (2012a). PGR5 ensures photosynthetic control to safeguard photosystem I under fluctuating light conditions. Plant Signal. Behav. 8, e22741. doi: $10.4161 /$ psb.22741

Suorsa, M., Jarvi, S., Grieco, M., Nurmi, M., Pietrzykowska, M., Rantala, M., etal. (2012b). PROTON GRADIENT REGULATION5 is essential for proper acclimation of Arabidopsis photosystem I to naturally and artificially fluctuating light conditions. Plant Cell 24, 2934-2948. doi: 10.1105/tpc.112. 097162

Suorsa, M., Sirpio, S., Allahverdiyeva, Y., Paakkarinen, V., Mamedov, F., Styring, S., et al. (2006). PsbR, a missing link in the assembly of the oxygenevolving complex of plant photosystem II. J. Biol. Chem. 281, 145-150. doi: 10.1074/jbc.M510600200

Suorsa, M., Sirpio, S., Paakkarinen, V., Kumari, N., Holmstrom, M., and Aro, E. M. (2010). Two proteins homologous to PsbQ are novel subunits of the chloroplast NAD(P)H dehydrogenase. Plant Cell Physiol. 51, 877-883. doi: $10.1093 / \mathrm{pcp} / \mathrm{pcq} 070$

Thuswaldner, S., Lagerstedt, J. O., Rojas-Stutz, M., Bouhidel, K., Der, C., LeborgneCastel, N., et al. (2007). Identification, expression, and functional analyses of a thylakoid ATP/ADP carrier from Arabidopsis. J. Biol. Chem. 282, 8848-8859. doi: 10.1074/jbc.M609130200

Tikhonov, A. N. (2013). pH-dependent regulation of electron transport and ATP synthesis in chloroplasts. Photosynth. Res. doi: 10.1007/s11120-013-9845-y

Tyystjärvi, E., and Aro, E. M. (1996). The rate constant of photoinhibition, measured in lincomycin-treated leaves, is directly proportional to light intensity. Proc. Natl. Acad. Sci. U.S.A. 93, 2213-2218. doi: 10.1073/pnas.93.5.2213 
Vasudevan, D., Fu, A., Luan, S., and Swaminathan, K. (2012). Crystal structure of Arabidopsis cyclophilin38 reveals a previously uncharacterized immunophilin fold and a possible autoinhibitory mechanism. Plant Cell 24, 2666-2674. doi: 10.1105/tpc.111.093781

Vener, A. V., Rokka, A., Fulgosi, H., Andersson, B., and Herrmann, R. G. (1999). A cyclophilin-regulated PP2A-like protein phosphatase in thylakoid membranes of plant chloroplasts. Biochemistry 38, 14955-14965. doi: 10.1021/ bi990971v

Wei, L., Guo, J., Ouyang, M., Sun, X., Ma, J., Chi, W., et al. (2010). LPA19, a Psb27 homolog in Arabidopsis thaliana, facilitates D1 protein precursor processing during PSII biogenesis. J. Biol. Chem. 285, 21391-21398. doi: 10.1074/jbc.M110.105064

Weigel, M., Varotto, C., Pesaresi, P., Finazzi, G., Rappaport, F., Salamini, F., et al. (2003). Plastocyanin is indispensable for photosynthetic electron flow in Arabidopsis thaliana. J. Biol. Chem. 278, 31286-31289. doi: 10.1074/jbc.M30 2876200

Wu, H. Y., Liu, M. S., Lin, T. P., and Cheng, Y. S. (2011). Structural and functional assays of AtTLP18.3 identify its novel acid phosphatase activity in thylakoid lumen. Plant Physiol. 157, 1015-1025. doi: 10.1104/pp.111.184739

Yabuta, S., Ifuku, K., Takabayashi, A., Ishihara, S., Ido, K., Ishikawa, N., et al (2010). Three PsbQ-like proteins are required for the function of the chloroplast NAD(P)H dehydrogenase complex in Arabidopsis. Plant Cell Physiol. 51, 866-876. doi: $10.1093 / \mathrm{pcp} / \mathrm{pcq} 060$

Yamamoto, H., Peng, L., Fukao, Y., and Shikanai, T. (2011). An Src homology 3 domain-like fold protein forms a ferredoxin binding site for the chloroplast NADH dehydrogenase-like complex in Arabidopsis. Plant Cell 23, 1480-1493. doi: 10.1105/tpc.110.080291

Yamamoto, Y., Inagaki, N., and Satoh, K. (2001). Overexpression and characterization of carboxyl-terminal processing protease for precursor D1 protein: regulation of enzyme-substrate interaction by molecular environments. J. Biol. Chem. 276 7518-7525. doi: 10.1074/jbc.M008877200

Yi, X., Hargett, S. R., Frankel, L. K., and Bricker, T. M. (2006). The PsbQ protein is required in Arabidopsis for photosystem II assembly/stability and photoautotrophy under low light conditions. J. Biol. Chem. 281, 26260-26267. doi: 10.1074/jbc.M603582200

Yi, X., Hargett, S. R., Frankel, L. K., and Bricker, T. M. (2009). The PsbP protein, but not the PsbQ protein, is required for normal thylakoid architecture in
Arabidopsis thaliana. FEBS Lett. 583, 2142-2147. doi: 10.1016/j.febslet.2009.05. 048

Yi, X., Hargett, S. R., Liu, H., Frankel, L. K., and Bricker, T. M. (2007). The PsbP protein is required for photosystem II complex assembly/stability and photoautotrophy in Arabidopsis thaliana. J. Biol. Chem. 282, 24833-24841. doi: 10.1074/jbc.M705011200

Yin, S., Sun, X., and Zhang, L. (2008). An Arabidopsis ctpA homologue is involved in the repair of photosystem II under high light. Chin. Sci. Bull. 53, 1021-1026. doi: 10.1007/s11434-008-0153-4

Yuan, J., Henry, R., McCaffery, M., and Cline, K. (1994). SecA homolog in protein transport within chloroplasts: evidence for endosymbiont-derived sorting. Science 266, 796-798. doi: 10.1126/science.7973633

Zhang, S., and Scheller, H. V. (2004). Photoinhibition of photosystem I at chilling temperature and subsequent recovery in Arabidopsis thaliana. Plant Cell Physiol. 45, 1595-1602. doi: 10.1093/pcp/pch180

Zienkiewicz, M., Ferenc, A., Wasilewska, W., and Romanowska, E. (2012). High light stimulates Deg1-dependent cleavage of the minor LHCII antenna proteins CP26 and CP29 and the PsbS protein in Arabidopsis thaliana. Planta 235, 279-288. doi: 10.1007/s00425-011-1505-x

Conflict of Interest Statement: The authors declare that the research was conducted in the absence of any commercial or financial relationships that could be construed as a potential conflict of interest.

Received: 17 July 2013; accepted: 12 October 2013; published online: 31 October 2013.

Citation: Järvi S, Gollan PJ and Aro E-M (2013) Understanding the roles of the thylakoid lumen in photosynthesis regulation. Front. Plant Sci. 4:434. doi: 10.3389/fpls.2013.00434

This article was submitted to Plant Physiology, a section of the journal Frontiers in Plant Science.

Copyright (C) 2013 Järvi, Gollan and Aro. This is an open-access article distributed under the terms of the Creative Commons Attribution License (CC BY). The use, distribution or reproduction in other forums is permitted, provided the original author(s) or licensor are credited and that the original publication in this journal is cited, in accordance with accepted academic practice. No use, distribution or reproduction is permitted which does not comply with these terms. 